\title{
Oncofertility and Fertility Preservation in Males: Current Perspective
}

\author{
Aditya P Sharma ${ }^{1}$, Ravimohan S Mavuduru² \\ Keywords: Cancer, Male infertility, Oncofertility. \\ Journal of Postgraduate Medicine Education and Research (2019): 10.5005/jp-journals-10028-1341
}

\section{INTRODUCTION}

Currently, about 2.5 million people are living with cancer in India. ${ }^{1}$ Indian Council of Medical Research (ICMR) projected that the total number of newly diagnosed cancer cases is going to reach nearly 17.3 lakh by $2020 .{ }^{2}$ Our country has more than $50 \%$ of its population below the age of 25 and more than $65 \%$ below the age of 35 and there is rise in incidence of cancer in adolescents and young adults (AYA). ${ }^{3}$ With an inverted population pyramid, cancer in AYA will constitute a significant burden in future.

With the advancements in cancer chemotherapeutic agents, oncological surgeries and radiotherapy the 5-years survival rates have also markedly improved. ${ }^{4,5}$ The 5 -year relative survival rate was $49 \%$ in $1975-1977$ compared to $67 \%$ in $2001-2007$. Most significant gains in 5-year relative survival is in pediatric patients (from 58\% in 1975-1977 to $83 \%$ in 2001-2007). ${ }^{4,5}$ These gains in survival especially in peripubertal male population have given rise to consideration and call for fertility preservation, as more and more cancer survivors are reaching a reproductive age. A whole new branch of oncofertility which deals with balancing lifesaving treatments against the fertility preserving options has flourished. ${ }^{6}$

The problem encountered in the adolescent patients is twofold. The cancer treatment and the consequential infertility lead to additional psychological distress. A possible solution offered in form of fertility preservation helps these patients to cope better with the cancer itself. ${ }^{7}$ Despite the options of adoption and gamete donation available to this cancer patient's majority declare a preference for fathering a biological child. A study by Schover et al. studied 724 men coming for semen cryopreservation at their center using a questionnaire pertaining to fertility preservation. ${ }^{7}$ They found that $51 \%$ of them would like to have children in future and rate increased to $77 \%$ when adjusting for those who were childless at diagnosis. ${ }^{7}$

\section{What Causes Infertility in Cancer Patients?}

The cause of infertility in patient with cancer is multifactorial.

Primary malignancy or the immune response to the cancer itself leads to infertility. ${ }^{8}$ Enhanced immune response, cytokine release, febrile status, multiple system impairment, chronic disease state and malnutrition all contribute to poor fertility status in these patients. ${ }^{8,9}$ Endocrine factors for example in germ cell tumors which release high levels of $\beta$-hCG affect spermatogenesis. Anti-sperm antibodies may be produced in malignant states and can lead to infertility. ${ }^{9}$ In 724 patients for sperm banking, Schover et al. found abnormal semen parameters in $64 \%{ }^{7}$
1,2Department of Urology, Advanced Urology Center, Nehru Hospital,
Postgraduate Institute of Medical Education and Research, Chandigarh,
India Corresponding Author: Ravimohan S Mavuduru, Department of Urology, Advanced Urology Center, Nehru Hospital, Postgraduate Institute of Medical Education and Research, Chandigarh, India, Phone: +91-9417532955, e-mail: ravismi2003@yahoo.com

How to cite this article: Sharma AP, Mavuduru RS. Oncofertility and Fertility Preservation in Males: Current Perspective. J Postgrad Med Edu Res 2019;53(4):176-178.

Source of support: Nil

Conflict of interest: None

High inguinal orchiectomy is standard of care for germ cell tumors. In cases of bilateral tumors or tumors of the solitary testes the surgery can render the patients infertile. Retroperitoneal lymph node dissection (RPLND) for testicular tumors can lead to alteration of ability to conceive through natural ejaculation by damaging the neurologic or functional mechanism of sperm delivery. ${ }^{10}$ Improvements in surgical technique, including testes sparing surgeries and nerve-sparing modifications for RPLND (Fig. 1) resections decrease ejaculatory dysfunction and consequential infertility. Prostatectomy, cystectomy, low anterior resection for colon cancer or any similar deep pelvic surgery can lead to damage to the vas deferens, ejaculatory duct, seminal vesicle, cavernous nerves or autonomic nerves thereby contributing to infertility.

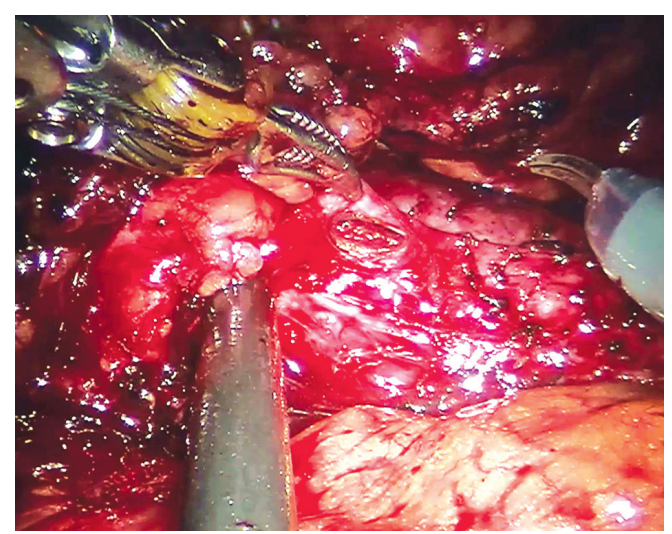

Fig. 1: Robot-assisted nerve-sparing retroperitoneal lymph node dissection in a patient of nonseminomatous germ cell tumor

(c) The Author(s). 2019 Open Access This article is distributed under the terms of the Creative Commons Attribution 4.0 International License (https://creativecommons. org/licenses/by-nc/4.0/), which permits unrestricted use, distribution, and non-commercial reproduction in any medium, provided you give appropriate credit to the original author(s) and the source, provide a link to the Creative Commons license, and indicate if changes were made. The Creative Commons Public Domain Dedication waiver (http://creativecommons.org/publicdomain/zero/1.0/) applies to the data made available in this article, unless otherwise stated. 
Chemoradiotherapy can lead to damage to the seminiferous tubules, including spermatogonial cells and steroli cells. ${ }^{11,12}$ Different chemotherapeutic drugs have varied effect when used in combination or alone. Alkylating agents such as cisplatin which are commonly used have a high risk of inducing infertility. ${ }^{11,12}$ Modification of chemotherapy regimens from one to other have been found to be of great value in preserving the fertility. For example, in patients of lymphoma transition from mechlorethamine, vincristine, procarbazine, and prednisone (MOPP) regime to doxorubicin, bleomycin, vinblastine, and dacarbazine (ABVD) has increased the fertility regain in these patients. ${ }^{12,13}$

Following radiation therapy timeline for sperm nadir and recovery is dose dependent. ${ }^{13,14}$ Lowest sperm counts frequently reported at 6 months following completion. Gonadoprotection in the form of mechanical and chemical shielding can be used for protection of fertility in these patients. ${ }^{13,14}$ Thus not only cancer but the treatment modalities used for cancer treatment including surgery, chemotherapy and radiotherapy all contribute to infertility.

\section{Semen Cryopreservation as the Cornerstone}

Semen cryopreservation remains the cornerstone of fertility preservation. ${ }^{10,13,15}$ The utilization rates of banked sperm are reported to be between $10 \%$ and $15 \%$. $^{10,16,17}$ The reason cited for the same are manifold. Some patients may recover sufficient levels of spermatogenesis posttreatment to sustain normal fertility. ${ }^{10,16}$ The studies have been criticized for limited follow-up and patients may utilize the cryopreserved sperm much later after follow-up. ${ }^{10}$ Patients may use their sperm after the study end date, resulting in an underreporting. Apart from this death of the patient due to cancer contributes to underutilization of the cryopreserved sperm.

Although cryopreservation decreases semen parameters upon thawing, with advances in in vitro fertilization (IVF)/intracytoplasmic sperm injection (ICSI) low number of viable sperms is needed for fertilization. Reported rates of fertilized sperms from cryopreserved sperms range from $26 \%$ to $55 \% .{ }^{17,18}$ Exact length till which cryopreserved sperm remains viable for is unknown. Successful paternity has been demonstrated with sperm cryopreserved up to 28 years. ${ }^{19}$ Menon et al. reported no difference in ICSI rates from cryopreserved semen of patients with testicular cancer, lymphomas and other tumors thereby implying that fertility rates remain the same despite the type of cancer. ${ }^{18}$

\section{URologist's Role}

Patient after thorough counseling submits sample for cryopreservation. Depending upon the quality of semen sample, number of vials is preserved. ${ }^{10,13}$ Usually $2-3$ samples are collected prior to cancer treatment. In case of anejaculation post ejaculatory urinalysis is assessed to rule out retrograde ejaculation. ${ }^{13,20}$ If significant sperms are found in post ejaculatory urine retrograde ejaculation is confirmed and the patient is started on alfa agonist such as pseudoephedrine or imipramine. ${ }^{13,20}$ In case of persistent retrograde ejaculation post-ejaculatory urine may be taken and sperms used after washing. Alternatively a catheter is placed in the bladder prior to ejaculation for bladder drainage and washed with sperm media. After removal of catheter the patient is asked to ejaculate. The catheter is reinserted and the bladder drained. The ejaculated sperms are centrifuged from the solution and resuspended in fresh media with cryoprotectant. In case of confirmed anejaculation vibratory stimulation or electroejaculation
Flowchart 1: Algorithm for fertility preservation in males

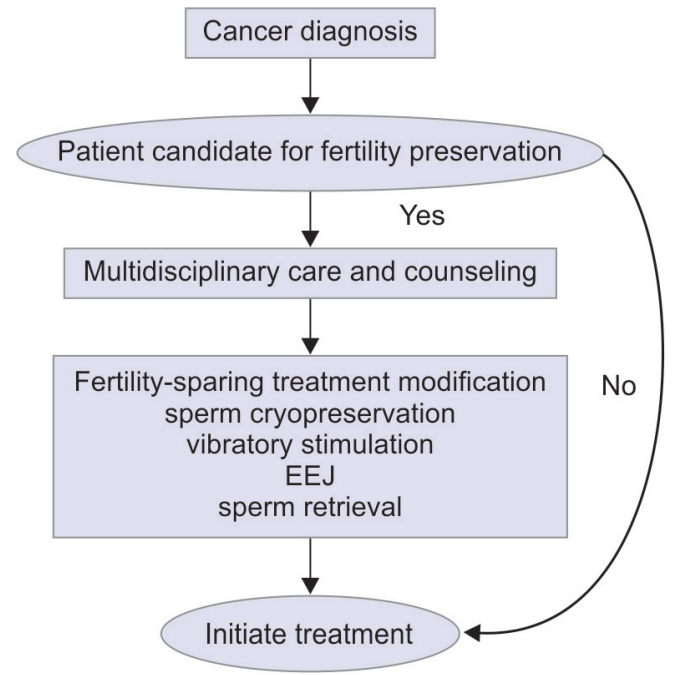

is performed to retrieve semen for cryopreservation..$^{13,20}$ In case of aspermia the sperm retrieval techniques such as microsurgical epididymal sperm aspiration (MESA), percutaneous epididymal sperm aspiration (PESA), testicular sperm aspiration (TESA) or microtesticular sperm extraction (TESE) are used and the retrieved sperms are cryopreserved ${ }^{13,20}$ (Flowchart 1).

\section{Barriers to Fertility Preservation}

Despite the availability of option of sperm cryopreservation for oncology patients there are barriers to the acceptance and utilization of this facility. ${ }^{10}$ On the part of physician and treating oncologists there is lack of knowledge about fertility preservation. ${ }^{10,21}$ There is lack of knowledge about the methods of fertility preservation, availability of local facilities for cryopreservation and so on. ${ }^{21,22}$ The cancer control takes priority over fertility preservation and thus fertility preservation takes a backseat over cancer control. There is lack of time in explaining the need and counsel regarding fertility preservation. ${ }^{21,22}$ There is perceived high-cost of semen cryopreservation.

On the part of patients there is lack of complete information regarding fertility preservation. ${ }^{10}$ Thirty percent to $60 \%$ of survivors reported that they did not receive information on risk of infertility from their healthcare team. ${ }^{21,22}$ Fear of unknown such as transmission of abnormal genetic material and passing of genetic material responsible for malignancy also leads to decrease utilization of this facility. ${ }^{13,22,23}$ Monetary issues especially in a country like ours where insurance system is still in infancy remain an important deterrent for using this facility. Religious beliefs, ethical and legal considerations remain another important barrier to fertility preservation.

Overcoming these barriers is a very important part in popularizing and patronizing fertility preservation. Increasing awareness both among the treating physicians, oncologists and patients alike about fertility preservation is the way ahead. Educational tools such as videos for educating patients suffering from cancer and candidates for fertility preservation will be a useful tool for increasing utilization of this facility. ${ }^{13,22,23}$ Dedicated man power in form of trained nurses earmarked for counseling, integrated in the oncofertility programs can be helpful in busy set ups catering to such large population of patients. With increasing 
utilization rates the running costs are bound to come down and can help in further acceptance and advocacy of sperm cryopreservation.

\section{The Future}

Fertility preservation in prepubertal males is still problematic as there are no mature sperm and spermarche are not known. ${ }^{13,24}$ Testicular tissue cryopreservation provides the greatest potential for these children. ${ }^{13,24}$ Pretreatment harvesting of testicular tissue with spermatogonial stem cell is a promising investigational tool. ${ }^{24-26}$ The difficulty in such harvesting and propagation is creation of complicated testicular microenvironment and induction of meiosis. ${ }^{24,25}$ There has been limited success with tissue harvesting and replantation in mice. Studies with human testicular tissue however, showed poor results and short-survival time for testicular tissue. ${ }^{13,24}$ A legitimate concern remains reintroduction of malignancy from a malignant testes limiting the use of this technique. However, studies are in full flow in this direction and future for these prepubertal boys with cancer and candidates for fertility preservation looks promising.

\section{Guidelines}

Both American Society of Clinical Oncology (ASCO) and American Society of Reproductive Medicine (ASRM) recommends addressing the importance of informing cancer patients about their potential risks of malignancy, treatment and available fertility preservation options. ${ }^{27,28}$ The only established methods for fertility preservation are sperm cryopreservation in males and embryo cryopreservation in females. ${ }^{27,28}$ Position statements provided by these societies deal with the nitty gritty of fertility preservation including medicolegal problems which may arise thereof. ${ }^{27,28}$

\section{Conclusion}

Oncofertility is a field that has grown remarkably in recent years. The education of patients and treating physicians/ oncologists, development of fertility preservation techniques and implementation of fertility preservation programs are advancing. A number of barriers remain for indictment of this strategy in routine practice. Cancer patients who are candidates for fertility preservation must be offered all the available information regarding fertility preservation.

\section{References}

1. Ingole SP, Kakde AU, Bonde PB. A review on statistics of cancer in india. IOSR J Environ Sci Toxicol Food Technol 2016;10(7):107-116. DOI: 10.9790/2402-100701107116.

2. Jyothi C. Economic burden of cancer in India. Indian J Public Health Res Dev 2017;8:137-141. DOI: 10.5958/0976-5506.2017.00175.9.

3. Inoue I, Nakamura F, Matsumoto K, et al. Cancer in adolescents and young adults: national incidence and characteristics in Japan. Cancer Epidemiol 2017;51:74-80. DOI: 10.1016/j.canep.2017.10.010.

4. Miller KD, Siegel RL, Lin CC, et al. Cancer treatment and survivorship statistics, 2016. CA Cancer J Clin 2016;66(4):271-289. DOI: 10.3322/ caac. 21349

5. DeSantis CE, Lin CC, Mariotto AB, et al. Cancer treatment and survivorship statistics, 2014. CA Cancer J Clin 2014;64(4):252-271. DOI: 10.3322/caac.21235.

6. Woodruff TK. The oncofertility consortium-addressing fertility in young people with cancer. Nat Rev Clin Oncol 2010;7(8):466-475. DOI: 10.1038/nrclinonc.2010.81.

7. Schover LR, Brey K, Lichtin A, et al. Knowledge and experience regarding cancer, infertility, and sperm banking in younger male survivors. J Clin Oncol 2002;20(7):1880-1889. DOI: 10.1200/ JCO.2002.07.175.

8. Lass A, Akagbosu F, Abusheikha N, et al. A programme of semen cryopreservation for patients with malignant disease in a tertiary infertility center: lessons from 8 years' experience. Hum Reprod 1998;13(11):3256-3261. DOI: 10.1093/humrep/13.11.3256.

9. Dohle GR. Male infertility in cancer patients: review of the literature. Int J Urol 2010;17(4):327-331. DOI: 10.1111/j.1442-2042.2010.02484.x.

10. Trost L, Brannigan R. Fertility preservation in males. In: Gracia C, Woodruff TK, ed. Oncofertility medical practice: clinical issues and implementation. DOI: 10.1007/978-1-4419-9425-7_3.

11. Ginsberg JP. New advances in fertility preservation for pediatric cancer patients. Curr Opin Pediatr 2011;23(1):9-13. DOI: 10.1097/ MOP.0b013e3283420fb6.

12. van der Kaaij MA, van Echten-Arends J, Simons AH, et al. Fertility preservation after chemotherapy for Hodgkin lymphoma. Hematol Oncol 2010;28(4):168-179. DOI: 10.1002/hon.939.

13. Katz DJ, Kolon TF, Feldman DR, et al. Fertility preservation strategies for male patients with cancer. Nat Rev Urol 2013;10(8):463-472. DOI: 10.1038/nrurol.2013.145.

14. Rowley MJ, Leach DR, Warner GA, et al. Effect of graded doses of ionizing radiation on the human testis. Radiat Res 1974;59(3):665-678. DOI: $10.2307 / 3574084$.

15. Hourvitz A, Goldschlag DE, Davis OK, et al. Intracytoplasmic sperm injection (ICSI) using cryopreserved sperm from men with malignant neoplasm yields high pregnancy rates. Fertil Steril 2008;90(3): 557-563. DOI: 10.1016/j.fertnstert.2007.03.002.

16. van Casteren NJ, van Santbrink EJ, van Inzen W, et al. Use rate and assisted reproduction technologies outcome of cryopreserved semen from 629 cancer patients. Fertil Steril 2008;90(6):2245-2250. DOI: 10.1016/j.fertnstert.2007.10.055.

17. Shin D, Lo KC, Lipshultz LI. Treatment options for the infertile male with cancer. J Natl Cancer Inst Monogr 2005(34):48-50. DOI: 10.1093/ jncimonographs/lgi004.

18. Menon S, Rives N, Mousset-Siméon N, et al. Fertility preservation in adolescent males: experience over 22 years at Rouen university hospital. Hum Reprod 2009;24(1):37-44. DOI: 10.1093/humrep/ den361.

19. Feldschuh J, Brassel J, Durso N, et al. Successful sperm storage for 28 years. Fertil Steril 2005;84(4):1017.DOI: 10.1016/j.fertnstert.2005.05.015.

20. Male SE. Infertility—Problems and Solutions Klein EA, ed., New York: Humana Press; 2011.

21. Schover LR, Brey K, Lichtin A, et al. Oncologists' attitudes and practices regarding banking sperm before cancer treatment. J Clin Oncol 2002;20(7):1890-1897. DOI: 10.1200/JCO.2002.07.174

22. Vadaparampil S, Quinn G, King L, et al. Barriers to fertility preservation among pediatric oncologists. Patient Educ Couns 2008;72(3):402-410. DOI: 10.1016/j.pec.2008.05.013.

23. Quinn GP, Vadaparampil ST, Bell-Ellison BA, et al. Patient-physician communication barriers regarding fertility preservation among newly diagnosed cancer patients. Soc Sci Med 2008;66(3):784-789. DOI: 10.1016/j.socscimed.2007.09.013.

24. Tournaye $H$, Dohle GR, Barratt CL. Fertility preservation in men with cancer. Lancet 2014;384(9950):1295-1301. DOI: 10.1016/S01406736(14)60495-5.

25. Tesarik J, Guido M, Mendoza C, et al. Human spermatogenesis in vitro: respective effects of follicle-stimulating hormone and testosterone on meiosis, spermiogenesis, and sertoli cell apoptosis. J Clin Endocrinol Metab 1998;83(12):4467-4473. DOI: 10.1210/jcem.83.12.5304.

26. Sadri-Ardekani H, Mizrak SC, van Daalen SK, et al. Propagation of human spermatogonial stem cells in vitro. JAMA 2009;302(19): 2127-2134. DOI: 10.1001/jama.2009.1689.

27. Oktay $\mathrm{K}$, Harvey $\mathrm{BE}$, Partridge $\mathrm{AH}$, et al. Fertility preservation in patients with cancer: ASCO clinical practice guideline update. J Clin Oncol 2018;36(19):1994-2001. DOI: 10.1200/JCO.2018.78.1914.

28. Ethics Committee of American Society for Reproductive Medicine. Fertility preservation and reproduction in patients facing gonadotoxic therapies: a committee opinion. Fertil Steril 2013;100(5):1224-1231. DOI: 10.1016/j.fertnstert.2013.08.041. 